\title{
Depression, 5HTTLPR and BDNFVal66Met polymorphisms, and plasma BDNF levels in hemodialysis patients with chronic renal failure
}

This article was published in the following Dove Press journal:

Neuropsychiatric Disease and Treatment

5 July 2014

Number of times this article has been viewed

\author{
Liang-Jen Wang ${ }^{1, *}$ \\ Chih-Ken Chen ${ }^{2,3, *}$ \\ Heng-Jung $\mathrm{Hsu}^{3,4}$ \\ I-Wen $\mathrm{Wu}^{3,4}$ \\ Chiao-Yin Sun ${ }^{3,4}$ \\ Chin-Chan Lee ${ }^{3,4}$ \\ 'Department of Child and Adolescent \\ Psychiatry, Kaohsiung Chang Gung \\ Memorial Hospital and Chang Gung \\ University College of Medicine, \\ Kaohsiung, Taiwan; '2Department of \\ Psychiatry, Chang Gung Memorial \\ Hospital, Keelung, Taiwan; ${ }^{3}$ Chang \\ Gung University School of Medicine, \\ Taoyuan, Taiwan; ${ }^{4}$ Department of \\ Nephrology, Chang Gung Memorial \\ Hospital, Keelung, Taiwan \\ *LJW and CKC are joint first authors \\ and contributed equally to this \\ manuscript
}

Correspondence: Chih-Ken Chen Department of Psychiatry, Chang Gung Memorial Hospital at Keelung, 222 Mai-Chin Road, Keelung, Taiwan Tel +8862 243292922717

Fax +886 2 243। 593 I

Email kenchen@cgmh.org.tw
Objective: Depression is the most prevalent comorbid psychiatric disease among hemodialysis patients with end-stage renal disease. This cross-sectional study investigated whether depression in hemodialysis patients is associated with the polymorphism of the $5^{\prime}$ flanking transcriptional region (5-HTTLPR) of the serotonin transporter gene, the valine (Val)-to-methionine (Met) substitution at codon 66 (Val66Met) polymorphism of the brain-derived neurotrophic factor $(B D N F)$ gene, or plasma BDNF levels.

Methods: A total of 188 participants (mean age: $58.5 \pm 14.0$ years; 89 men and 99 women) receiving hemodialysis at the Chang Gung Memorial Hospital were recruited. The diagnosis of major depressive disorder (MDD) was confirmed using the Chinese version of the Mini International Neuropsychiatric Interview. The genotypes of 5-HTTLPR and BDNF Val66Met were conducted using polymerase chain reactions plus restriction fragment length polymorphism analysis. The plasma BDNF levels were measured using an enzyme-linked immunosorbent assay kit.

Results: Forty-five (23.9\%) patients fulfilled the Diagnostic and Statistical Manual of Mental Disorders, Fourth Edition (DSM-IV-TR) criteria for a MDD. There were no significant effects of the 5-HTTLPR or BDNF Val66Met gene polymorphism on MDD among the hemodialysis patients. The plasma BDNF levels correlated significantly with age $(P=0.003)$ and sex $(P=0.047)$ but not with depression, the genotypes of 5-HTTLPR and BDNF Val66Met, the current antidepressant treatment, or the duration under hemodialysis.

Conclusion: Our results did not support the hypothesis of an involvement of the 5HTTLPR and BDNF Val66Met genotypes, or plasma BDNF levels in the pathogenesis of depression, in patients receiving hemodialysis. A study with a large sample size and homogenous patient group is warranted to confirm these findings.

Keywords: mood disorder, BDNF, serotonin, gene, hemodialysis, medical disease

\section{Introduction}

Renal disease is common throughout the world, and approximately $90 \%$ of patients with end-stage renal disease (ESRD) begin renal replacement therapy with hemodialysis. ${ }^{1}$ Hemodialysis is a lifelong treatment that frequently leads to adverse effects on patients' mental health. ${ }^{2}$ Depression is the most prevalent comorbid psychiatric disease, estimated to occur in about $20 \%$ to $30 \%$ of hemodialysis patients. ${ }^{3,4}$ Strong correlations have been reported between depression and longitudinal outcome, including poor treatment adherence and higher mortality rates. ${ }^{5}$ Determining the pathogenesis of depression among hemodialysis patients is therefore important. The etiology of dialysisrelated depression is multifactorial, related to biological, psychological, and social mechanisms. Regarding the biological mechanisms, neurotransmitters, inflammation, 
nutritional status, and possible genetic predisposition have all been proposed as potential pathogenesis. ${ }^{6-8}$

For some time, a gene-environment interaction has been recognized in the pathophysiology of depression. ${ }^{9}$ The gene expression linking to the serotonergic system, in particular, plays a crucial role in depression. Among the various components of the serotonergic system, the serotonin transporter protein (5-HTT) is critically important in regulating the reuptake of serotonin into the presynaptic neuron, serving as a target site for certain antidepressants. ${ }^{10}$ Allelic variations in the $5^{\prime}$ flanking transcriptional region (5-HTTLPR), which controls 5-HTT expression and function of the 5-HTT gene, have been reported as associated with depression. ${ }^{11}$ The 5-HTTLPR polymorphism comprises a 43-base pair (bp) insertion or deletion (long [L] or short [S] alleles, respectively). ${ }^{12}$ Regarding the functional significance of novel allelic variants at this site, the long $\mathrm{G}\left(\mathrm{L}_{\mathrm{G}}\right)$ and $\mathrm{S}$ alleles of the 5-HTTLPR gene have comparable levels of serotonin transporter expression and depression, and both have lower expression than that of the long $\mathrm{A}\left(\mathrm{L}_{\mathrm{A}}\right)$ allele. ${ }^{13}$

The brain-derived neurotrophic factor (BDNF), an important member of the neurotrophin family, is able to cross the blood-brain barrier. BDNF promotes the survival, differentiation, and maintenance of neurons in the peripheral and central nervous systems. ${ }^{14} \mathrm{~A}$ functional polymorphism in the human $B D N F$ gene (single nucleotide polymorphism database [dbSNP] number rs6265) has been identified as producing a valine (Val)-to-methionine (Met) substitution at codon 66 (Val66Met). ${ }^{15}$ The debate on whether the functional Val66Met polymorphism could serve as a biomarker of mood disorders has lasted for a decade. ${ }^{16} \mathrm{~A}$ recent meta-analysis did not detect a significant association between single nucleotide polymorphisms (SNPs) in the $B D N F$ with major depressive disorder (MDD). ${ }^{17}$ Nevertheless, coping styles and perceived coping flexibility after life stress are potentially moderated by the presence of a BDNF Val66Met polymorphism associated with neurotrophic support. ${ }^{18}$ Some researchers have reported that the BDNF Val66Met polymorphism is a susceptibility factor for depression in patients with specific medical illnesses, including poststroke patients ${ }^{19}$ and breast cancer patients after mastectomies..$^{20}$ To date, it remains unknown whether BDNF Val66Met polymorphisms play a role in the pathogenesis of depression among hemodialysis patients.

The activity in the serotonin system is likely regulated by BDNF. ${ }^{21}$ Compelling evidence indicates that both plasma and serum levels of BDNF have been considered as biomarkers for major depression. ${ }^{22,23} \mathrm{~A}$ recent meta-analysis study reported that the levels of BDNF in drug-naïve patients with depressive disorders were significantly lower than those in healthy controls. ${ }^{24}$ Moreover, antidepressant treatment could cause BDNF levels to become normal. ${ }^{25,26}$ However, there have been no studies specifically investigating the relationships between depression and BDNF levels in patients requiring hemodialysis. Thus, it has not yet been determined whether BDNF levels also serve as a biomarker for dialysis-related depression.

Accordingly, the current study aimed to investigate whether 5-HTTLPR and BDNF Val66Met genotypes are involved in the pathogenesis of depression in patients with ESRD receiving hemodialysis, and to elucidate the relationships between plasma BDNF levels and depression in this patient group.

\section{Method}

\section{Participants}

In this cross-sectional study, 200 patients who were aged 18 years or more and receiving hemodialysis at the Chang Gung Memorial Hospital, Keelung between 2007 and 2009 were enrolled. The methods used for case recruitment, study procedures, and the measurement tools have been described elsewhere in detail. ${ }^{27}$ The key points are briefly summarized in the following section. Each participant was initially interviewed by an attending psychiatrist. The diagnosis of MDD was confirmed by a research team member trained in the use of the Diagnostic and Statistical Manual of Mental Disorders, Fourth Edition (DSM-IV-TR) ${ }^{28}$ criteria and the Chinese version of the Mini International Neuropsychiatric Interview (MINI) ${ }^{29}$ The interrater reliability of the Chinese version of the MINI, translated by the Taiwan Society of Psychiatry, was preestablished. ${ }^{30}$ In addition, all the hemodialysis patients underwent assessments for depressive and anxiety symptoms, using the Hospital Anxiety and Depression Scale (HADS) $;{ }^{31}$ for fatigue symptoms, using the Chalder Fatigue Scale (CFS); ${ }^{32}$ and for health-related quality of life, using the Short-Form $\left(\right.$ SF-36 ${ }^{\circledR}$ ) Health Survey. ${ }^{33}$ Written informed consent was obtained from each patient prior to participation. The Institutional Review Board at the Chang Gung Memorial Hospital approved this study.

\section{Blood samples and genotyping}

Venous blood was collected from patients at the beginning of their hemodialysis session. All of the blood samples obtained were assayed within a single assay batch and then frozen and stored at $-80^{\circ} \mathrm{C}$ until the measurement of plasma BDNF levels and genotyping. The plasma BDNF levels were measured using an enzyme-linked immunosorbent assay (ELISA) kit (Promega Corp, Fitchburg, WI, USA), after appropriate 
dilution of samples $(1: 10$ to $1: 50)$ in blocking and sample buffer according to manufacturer instructions. ${ }^{34}$ The plasma BDNF levels were expressed as $\mathrm{pg} / \mathrm{mL}$, and the detection sensitivity of BDNF was $15.6 \mathrm{pg} / \mathrm{mL}$. The absorbance of samples was measured with an automated microplate reader at $450 \mathrm{~nm}$. The BDNF concentrations were determined automatically according to the BDNF standard curve (ranging from 7.8 to $500 \mathrm{pg} / \mathrm{mL}$ of BDNF).

Genomic DNA was extracted from the peripheral blood samples by standard methods. The polymerase chain reaction (PCR) amplification was performed in a total volume of $20 \mu \mathrm{L}$ containing $2 \mu \mathrm{L}$ of $10 \times$ PCR buffer, $1 \mu \mathrm{L}$ dimethylsulfoxide, $2.5 \mathrm{nM}$ deoxyribonucleotide triphosphate (dNTP), $3.2 \mu \mathrm{L}$ of $50 \%$ glycerol, $5 \mu \mathrm{M}$ of each primer and $1.5 \mathrm{U}$ Taq deoxyribonucleic acid (DNA) polymerase. The PCR amplification consisted of $95^{\circ} \mathrm{C}$ for 5 minutes, followed by 40 cycles of $95^{\circ} \mathrm{C}$ for 30 seconds, $62^{\circ} \mathrm{C}$ for 30 seconds, and $72^{\circ} \mathrm{C}$ for 30 seconds before a final extension step at $72^{\circ} \mathrm{C}$ for 7 minutes. The PCR products were separated by $3 \%$ agarose gel. Genotyping of the 5-HTTLPR polymorphisms was accomplished in two stages: stage 1 was aimed at distinguishing the $\mathrm{S}$ from the $\mathrm{L}$ alleles; and stage 2 distinguished the $\mathrm{L}_{\mathrm{A}}$ from the $\mathrm{L}_{\mathrm{G}}$ allele. For stage 1, the sense and antisense primers used for the 5-HTTLPR were 5'-GGC GTT GCC GCT CTG AAT GC-3' and 5'-GAG GGA CTG AGC TGG ACA ACC AC 3'. For stage 2 , the primers for sequencing were the same as those used in the stage 1 genotype. The BDNF Val66Met genotype was determined using PCR amplification and restriction digest. The PCR amplification of the participant DNA was undertaken using the primers 5'-TGT ATT CCT CCA GCA GAA AGA GAA-3' and 5'-AAA GAA GCA AAC ATC CGA GGA C-3' and standard conditions. The amplified fragments were digested with the restriction enzyme Afl III. For the 5-HTTLPR polymorphism, the genotypes were categorized as $\mathrm{S} / \mathrm{S}, \mathrm{S} / \mathrm{L}_{\mathrm{G}}, \mathrm{L}_{\mathrm{G}} / \mathrm{L}_{\mathrm{G}}, \mathrm{S} / \mathrm{L}_{\mathrm{A}}, \mathrm{L}_{\mathrm{G}} / \mathrm{L}_{\mathrm{A}}$, and $\mathrm{L}_{\mathrm{A}} / \mathrm{L}_{\mathrm{A}}$. For the BDNF Val66Met polymorphism, the genotypes were categorized as Val/Val, Val/Met, and Met/Met. The laboratory technician who did the genotyping and read out the genotype data was blinded to the patients' diagnoses.

\section{Data analysis}

The statistical analyses were conducted using SPSS 16.0 for Windows (SPSS Inc., Chicago, IL, USA). The variables were presented as the mean \pm standard deviation (SD) or frequency. All the tests were two-tailed, and the level of significance was $P<0.05$.

The participants for whom either the plasma BDNF level or the BDNF Val66Met or 5HTTLPR polymorphism data were unavailable were excluded from the analyses $(\mathrm{N}=12)$. The differences in the sex and genotype frequencies of the 5-HTTLPR and BDNF polymorphisms between the patients with MDD and without MDD were calculated using Pearson's $\chi^{2}$ test. Fisher's exact test was substituted for the $\chi^{2}$ test when the cells were smaller $(<5)$ than expected values. The demographic and clinical variables involving continuous data were analyzed using the Student's $t$-test, while the MannWhitney $U$ test was used if the data violated the normal distribution. The Pearson's or Spearman's correlations were used to evaluate the associations between BDNF levels and the other continuous variables. A logistic regression was used to examine the possible effects of 5-HTTLPR and BDNF gene polymorphisms for the risk of MDD. The 5-HTTLPR and BDNF alleles were recoded as binary variables, thus, BDNF Val66Met non-Met carrier (Val/Val) versus Met carrier (Val/Met or Met/Met), to examine the effects of the BDNF Met allele as a vulnerability factor; and 5-HTTLPR non-LA carrier (S/S, S/LG, or LG/LG) versus LA carrier (S/LA, LG/ LA, or LA/LA), to examine the effects of the 5-HTTLPR LA allele as a protective factor. This classification method has been adopted in earlier studies. ${ }^{35-37}$ The associations were expressed as odds ratios (ORs) with corresponding 95\% confidence intervals.

\section{Results}

A total of 188 patients on hemodialysis ( 89 men and 99 women), with a mean age of $58.5 \pm 14.0$ years, were included in the analyses. Of the 188 subjects, 45 (23.9\%) fulfilled the DSM-IV criteria for MDD. Of the total participants, ten currently received treatment with antidepressant drugs (ie, six with amitriptyline; two with mirtazapine; one with escitalopram; and one with paroxetine). For the six patients treated with amitriptyline, the prescription was mainly for the symptoms of insomnia, rather than depression. Compared with patients without MDD, the patients with MDD had a higher rate of current antidepressant treatment $(P=0.015)$, higher scores on the depression subscale $(P<0.001)$ and anxiety subscale $(P<0.001)$ in the HADS, higher fatigue scores in the CFS $(P<0.001)$, and lower scores in the mental component summary in the SF-36 $(P<0.001)$. There was no significant difference in other characteristics, between the patients with and without MDD (Table 1).

The genotype distributions of 5-HTTLPR and BDNF Val66Met were in Hardy-Weinberg equilibrium, both in the hemodialysis patients with MDD and those without MDD. The distribution of the 5-HTTLPR $(P=0.953)$ and BDNF Val66Met $(P=0.539)$ genotypes were not significantly 
Table I Demographic characteristics of hemodialysis patients with and without MDD

\begin{tabular}{|c|c|c|c|c|}
\hline & Without MDD $(n=143)$ & With MDD $(n=45)$ & Statistic & $P$-value \\
\hline Age (years) & $58.9 \pm 14.0$ & $57.4 \pm 13.8$ & $t=0.627$ & 0.532 \\
\hline Male/female, $n(\%)$ & $70(49.0) / 73(51.0)$ & $19(42.2) / 26(57.8)$ & $\chi^{2}=0.622$ & 0.495 \\
\hline Smoke, n (\%) & $32(22.4)$ & $6(13.3)$ & $\chi^{2}=1.736$ & 0.210 \\
\hline Alcohol use, $n(\%)$ & $15(10.5)$ & $6(13.3)$ & $\chi^{2}=0.279$ & 0.787 \\
\hline Current antidepressant treatment, $\mathrm{n}(\%)$ & $4(2.8)^{\mathrm{a}}$ & $6(13.3)^{b}$ & $\chi^{2}=7.275$ & $0.015^{*}$ \\
\hline Body mass index $\left(\mathrm{kg} / \mathrm{m}^{2}\right)$ & $23.2 \pm 4.0$ & $23.7 \pm 4.2$ & $t=0.678$ & 0.499 \\
\hline Hemodialysis duration (months) & $70.6 \pm 68.4$ & $52.8 \pm 51.6$ & $t=1.601$ & 0.111 \\
\hline Number of comorbid diseases & $1.9 \pm 1.5$ & $2.2 \pm 2.0$ & $t=0.667$ & 0.507 \\
\hline Depression score in HADS & $4.7 \pm 4.3$ & $11.9 \pm 5.8$ & $t=7.644$ & $<0.00$ I*** \\
\hline Anxiety score in HADS & $3.7 \pm 3.4$ & $7.5 \pm 4.8$ & $t=4.943$ & $<0.001 * * *$ \\
\hline Fatigue score in CFS & $22.4 \pm 6.8$ & $31.6 \pm 7.7$ & $t=7.619$ & $<0.001 * * *$ \\
\hline Physical component summary in SF-36 & $53.9 \pm 26.2$ & $47.1 \pm 28.6$ & $t=1.48 \mid$ & 0.140 \\
\hline Mental component summary in SF-36 & $75.3 \pm 24.5$ & $38.1 \pm 26.5$ & $t=8.595$ & $<0.00 I^{* * *}$ \\
\hline
\end{tabular}

Notes: aAmitriptyline $(n=4)$; bamitriptyline $(n=2)$, mirtazapine $(n=2)$, escitalopram $(n=I)$, paroxetine $(n=I) ; * P<0.05 ; * * * P<0.00 I$.

Abbreviations: CFS, Chalder Fatigue Scale; HADS, Hospital Anxiety and Depression Scale; MDD, major depressive disorder; SF-36 ${ }^{\circledR}$, the Short-Form Health survey (healthrelated quality of life).

different between the patients with and without MDD (Table 2). After the 5-HTTLPR and BDNF alleles were recoded as binary variables, significant differences in MDD were not found between either the 5-HTTLPR genotypes (non-LA carrier versus LA carrier) $(P=0.606)$ or between the BDNF Val66Met genotypes (non-Met carrier versus Met carrier) $(P=0.846)$. The genotypes of 5-HTTLPR and BDNF Val66Met were also not significantly associated with the scores for depression, anxiety, fatigue, or quality of life.

Among the total participants, the plasma BDNF levels were $755.4 \pm 214.3 \mathrm{pg} / \mathrm{mL}$. The BDNF levels showed a significantly negative correlation with age $(r=-0.21, P=0.003)$ but no significant correlation with body mass index ( $r=0.05$, $P=0.471)$, duration of receiving hemodialysis $(r=0.07$, $P=0.338)$, number of comorbid diseases $(r=-0.10, P=0.190)$, depression score in the HADS ( $r=0.02, P=0.797)$, anxiety score in the HADS $(r=0.08, P=0.248)$, fatigue score in the CFS ( $r=0.13, P=0.070$ ), or the physical component summary $(r=-0.01, P=0.885)$ and mental component summary $(r=-0.07$,
$P=0.374$ ) of the SF-36. The plasma BDNF levels were then compared between sexes, patients with or without MDD, patients with or without current antidepressant treatment, and the binary genotypes of 5-HTTLPR and BDNF Val66Met (Table 3). Higher BDNF levels were found in women than in men (women: $763.6 \pm 205.9 \mathrm{pg} / \mathrm{mL}$; men: $719.7 \pm 222.9 \mathrm{pg} / \mathrm{mL}$ ) $(P=0.047)$. However, the levels of BDNF did not differ significantly between patients with or without MDD ( $P=0.723)$, patients with or without current antidepressant treatment ( $P=0.716$ ), or between the 5-HTTLPR genotypes $(P=0.837$ ) and $B D N F$ Val66Met genotypes $(P=0.516)$.

To avoid the confounding effects on BDNF of antidepressant drugs, we analyzed the data further for antidepressant-free patients $(\mathrm{N}=178)$. The levels of significant findings remain the same as those for the overall group of participants. There was no significant main effect or interaction effect of the 5-HTTLPR or BDNF gene polymorphisms on MDD. The plasma BDNF levels showed a significant association with age $(r=-0.21, P=0.004)$ and sex

Table 2 Genotype distribution of the 5HTTLPR and BDNF Val66Met polymorphism in hemodialysis patients

\begin{tabular}{|c|c|c|c|c|c|c|c|c|c|c|c|c|c|}
\hline & \multicolumn{6}{|c|}{ 5HTTLPR genotype } & \multirow[t]{2}{*}{$\chi^{2}$} & \multirow[t]{2}{*}{$P$-value } & \multicolumn{3}{|c|}{ BDNF Val66Met genotype } & \multirow[t]{2}{*}{$\chi^{2}$} & \multirow[t]{2}{*}{$P$-value } \\
\hline & $\mathbf{S} / \mathbf{S}$ & $S / L_{G}$ & $\mathbf{L}_{G} / \mathbf{L}_{G}$ & $S / L_{A}$ & $\mathbf{L}_{G} / \mathbf{L}_{A}$ & $\mathbf{L}_{A} / \mathbf{L}_{A}$ & & & Val/Val & Val/Met & Met/Met & & \\
\hline $\begin{array}{l}\text { No MDD, } \\
\text { n (\%) }\end{array}$ & $77(53.8)$ & $6(4.2)$ & $3(2.1)$ & $48(33.6)$ & $6(4.2)$ & $3(2.1)$ & 1.466 & 0.953 & $36(25.2)$ & $60(42.0)$ & $47(32.9)$ & 1.194 & 0.539 \\
\hline \multirow[t]{2}{*}{ MDD, n (\%) } & $22(48.9)$ & $2(4.4)$ & I (2.2) & I8 (40.0) & $2(4.4)$ & $0(0)$ & & & $12(26.7)$ & $22(48.9)$ & II (24.4) & & \\
\hline & \multicolumn{3}{|c|}{ Non- $\mathrm{L}_{A}$ carrier } & \multicolumn{3}{|c|}{$\mathbf{L}_{A}$ carrier } & $\chi^{2}$ & $P$-value & $\begin{array}{l}\text { Non-Met } \\
\text { carrier }\end{array}$ & \multicolumn{2}{|c|}{ Met carrier } & $\chi^{2}$ & $P$-value \\
\hline $\begin{array}{l}\text { No MDD, } \\
n(\%)\end{array}$ & \multicolumn{3}{|l|}{$86(60.1)$} & \multicolumn{3}{|l|}{$57(39.9)$} & 0.297 & 0.606 & $36(25.2)$ & \multicolumn{2}{|l|}{$107(74.8)$} & 0.040 & 0.846 \\
\hline MDD, n (\%) & \multicolumn{3}{|l|}{$25(55.6)$} & \multicolumn{3}{|l|}{$20(44.4)$} & & & $12(26.7)$ & \multicolumn{2}{|l|}{$33(73.3)$} & & \\
\hline
\end{tabular}

Abbreviations: $5 H$ TTLPR, $5^{\prime}$ flanking transcriptional region of the serotonin transporter gene; BDNF, brain-derived neurotrophic factor; $L$, long; $L_{A}$, long $A$; $L_{G}$, long $G$; MDD, major depressive disorder; Met, methionine; S, short; Val, valine; Val66Met, Val-to-Met substitution at codon 66. 
Table 3 The plasma BDNF level determined in relation to major depressive disorder (MDD), sex, current antidepressant treatment, 5HTTLPR genotype and BDNF Val66Met genotype among hemodialysis patients

\begin{tabular}{|c|c|c|c|}
\hline Characteristics & $\begin{array}{l}\text { Plasma BDNF } \\
\text { level (pg/mL) }\end{array}$ & Statistic & $P$-value \\
\hline \multicolumn{4}{|l|}{ MDD } \\
\hline Without MDD $(n=\mid 43)$ & $748.4 \pm 217.6$ & $t=0.355$ & 0.723 \\
\hline With MDD $(n=45)$ & $762.1 \pm 222.0$ & & \\
\hline \multicolumn{4}{|l|}{ Sex } \\
\hline Male $(n=89)$ & $719.7 \pm 222.9$ & $t=2.004$ & $0.047^{*}$ \\
\hline Female $(n=99)$ & $783.6 \pm 205.9$ & & \\
\hline \multicolumn{4}{|c|}{ Current antidepressant treatment } \\
\hline Without $(n=178)$ & $752.1 \pm 217.4$ & $Z=0.363$ & 0.716 \\
\hline With $(n=10)$ & $789.1 \pm 173.6$ & & \\
\hline \multicolumn{4}{|l|}{ 5HTTLPR genotype } \\
\hline Non- $\mathrm{L}_{\mathrm{A}}$ carrier $(\mathrm{n}=\mathrm{III})$ & $755.3 \pm 222.3$ & $t=0.207$ & 0.837 \\
\hline $\mathrm{L}_{\mathrm{A}}$ carrier $(\mathrm{n}=77)$ & $748.5 \pm 211.1$ & & \\
\hline \multicolumn{4}{|l|}{ BDNF Val66Met genotype } \\
\hline Non-Met carrier $(n=48)$ & $771.1 \pm 190.3$ & $t=0.65$ I & 0.516 \\
\hline Met carrier $(n=140)$ & $746.6 \pm 224.1$ & & \\
\hline
\end{tabular}

Note: $* P<0.05$.

Abbreviations: 5HTTLPR, $5^{\prime}$ flanking transcriptional region of the serotonin transporter gene; $B D N F$, brain-derived neurotrophic factor; $L_{\mathrm{A}}$, long $A ; M D D$, major depressive disorder; Met, methionine; Val, valine; Val66Met, Val-to-Met substitution at codon 66

(women: $787.5 \pm 204.7 \mathrm{pg} / \mathrm{mL}$; men: $716.5 \pm 224.7 \mathrm{pg} / \mathrm{mL}$ ) $(P=0.029)$ but not with the other variables.

\section{Discussion}

The main findings from this study did not support the possible involvement of 5-HTTLPR and BDNF Val66Met polymorphisms in the pathophysiology of MDD, among patients receiving hemodialysis. Previously, the 5HTTLPR polymorphism has long been proposed to have a potential role in the pathogenesis of depression. ${ }^{11}$ However, recent studies with large samples have indicated no support for the hypothesis of the interaction effect of 5HTTLPR genotype and stress in the development of depression or suicidal tendencies. ${ }^{12,38}$ The $B D N F$ Val66Met polymorphism has been demonstrated to have a significant effect on depression and the treatment response to antidepressants; however, such findings were not consistent between studies. ${ }^{14,39}$ The differences in study population and in the definition of depression are likely to have contributed to the incomparable results. In sum, the role of the 5-HTTLPR and BDNF Val66Met polymorphisms in the etiology of depression continues to be debated. Nevertheless, it is noteworthy that the sample size was small in our study. The negative finding regarding gene polymorphisms in depression might be explained by the insufficient statistical power.
Regarding the effect of the BDNF Val66Met genotype on BDNF levels, the serum BDNF level for Met-carrier subjects has been found to be lower than for Val homozygote subjects. ${ }^{35,36}$ Furthermore, Bhang et al reported that the serum BDNF level in 5-HTTLPR S homozygote subjects was lower than that in L-carrier subjects. ${ }^{36}$ Nevertheless, we did not find any association between plasma BDNF levels and the 5-HTTLPR or BDNF Val66Met genotypes. To the best of our knowledge, we are the only team investigating plasma BDNF levels among ESRD patients on hemodialysis. Amongst healthy subjects, it was found that a large amount of BDNF was sequestered from blood and stored in platelets. ${ }^{40}$ Nevertheless, the extent to which BDNF levels are influenced by renal disease or the process of hemodialysis remains unclear. Therefore, whether renal disease or hemodialysis counteracts the potential association of BDNF levels, depression, and the genotypes of 5HTTLPR and BDNF Val66Met warrants further investigation.

We did not find any significant correlation between plasma BDNF levels and depression. Current evidence generally indicates that patients with depressive disorders carry significantly lower serum levels of BDNF compared with healthy controls. ${ }^{22,24}$ However, the differences were less consistent among the studies that determined the BDNF levels using plasma. ${ }^{24}$ Regarding patients with specific medical illnesses, Kobayakawa et al reported no significant association for depression and serum BDNF levels, in patients with lung cancer. ${ }^{41}$ Fabregas et al demonstrated that plasma BDNF levels were similar between depressed and nondepressed patients with chronic hepatitis C. ${ }^{42}$ However, there are plausible explanations for the differences in the findings between the studies. One such explanation is the discrepancy in samples and materials. Due to the different amounts of BDNF contained by platelets, the serum levels of BDNF have been shown to be 200 -fold higher than plasma levels. ${ }^{43}$ Therefore, a distinct biological significance of serum and plasma BDNF might exist. ${ }^{44}$ Furthermore, the changes in BDNF levels might be influenced by immune dysregulation among patients with comorbidities. ${ }^{41,42}$ During hemodialysis, the blood-dialyzer interaction has the potential to activate patients' immune response ${ }^{45}$ and this may further affect their BDNF production.

Notable findings in the study reported here were that the plasma BDNF levels decreased significantly with increasing age and that women had higher BDNF levels than men. The finding of a correlation between BDNF levels and age conflicted with previous studies that investigated the similar topic. ${ }^{40,46,47}$ Regarding sex differences, Lommatzsch et al 
reported that women had significantly higher plasma BDNF levels than men but that the sex differences disappeared after being matched for weight. ${ }^{40}$ Elfving et al suggested that there is no sex difference in serum BDNF levels. ${ }^{47}$ Intriguingly, while we controlled the covariate effects of age and body weight (data not shown), sex still showed an independent effect on plasma BDNF levels $(P=0.024)$ in our study population. The decreasing expression of the high-affinity BDNF receptor neurotrophic tyrosine kinase receptor 2 (TrkB) along with aging has been postulated as a possible mechanism underlying the negative correlation between age and BDNF levels. ${ }^{48}$ On the other hand, BDNF levels could be altered by sex hormones and menstrual cycles in women, and changes in serum BDNF levels with age have been found to be less pronounced in men. ${ }^{46}$ Taken together, ongoing research is needed to elucidate whether plasma BDNF levels are affected by age or sex or their interaction.

The study has several notable limitations, outlined here. First, the study population was small for a genetic study. The small sample size reduced the statistical power and might have been insufficient to detect the possible effects of gene polymorphisms in depression. Second, patients receiving hemodialysis commonly have comorbidities; in addition, the biological impact of physical illnesses on depression may differ according to the time elapsed from disease onset. These issues could have distorted the results. In addition, some information about the MDD diagnosis was not identified (ie, length of diagnosis, number of prior episodes, and comorbid anxiety diagnoses). A more homogenous patient group, controlled for other physical illnesses, should be recruited in the future in order to validate our findings. Third, the blood samples were collected from patients at the beginning of their hemodialysis session, not at a fixed time during the day. The diurnal variation could also have influenced the plasma BDNF levels in this study. Furthermore, BDNF was measured in plasma (containing platelets, which accumulate BDNF internally), but not in serum. This complicates the interpretation of BDNF levels. Finally, the plasma BDNF levels could have been influenced by antidepressant medications or sex hormones. However, we did not identify the duration of antidepressant treatment for all participants, nor did we identify the phase of the menstrual cycle in the female participants. The potential confounding effect of these factors could have affected the results.

\section{Conclusion}

The findings presented in this study did not support the hypothesis of the involvement of the 5-HTTLPR and BDNF Val66Met genotypes, or plasma BDNF levels in the pathogenesis of depression in patients receiving hemodialysis. The plasma BDNF levels were significantly correlated with age and sex but were not correlated with the measures of depression or the genotypes of 5-HTTLPR and BDNF Val66Met. A future study with large sample size and homogenous patient group appears necessary to confirm these findings.

\section{Acknowledgments}

This study was supported by the National Science Council, Taiwan (NSC 96-2314-B-182A-090-MY2). The authors wish to express their deepest gratitude to all the patients who participated in this study.

\section{Disclosure}

The authors report no conflicts of interest in this work.

\section{References}

1. Kimmel PL, Peterson RA. Depression in end-stage renal disease patients treated with hemodialysis: tools, correlates, outcomes, and needs. Semin Dial. 2005;18(2):91-97.

2. Kimmel PL. Psychosocial factors in dialysis patients. Kidney Int. 2001;59(4):1599-1613.

3. Chilcot J, Wellsted D, Da Silva-Gane M, Farrington K. Depression on dialysis. Nephron Clin Pract. 2008;108(4):c256-c264.

4. Halen NV, Cukor D, Constantiner M, Kimmel PL. Depression and mortality in end-stage renal disease. Curr Psychiatry Rep. 2012;14(1): $36-44$.

5. Drayer RA, Piraino B, Reynolds CF 3rd, et al. Characteristics of depression in hemodialysis patients: symptoms, quality of life and mortality risk. Gen Hosp Psychiatry. 2006;28(4):306-312.

6. Cukor D, Peterson RA, Cohen SD, Kimmel PL. Depression in end-stage renal disease hemodialysis patients. Nat Clin Pract Nephrol. 2006;2(12): 678-687.

7. Hung KC, Wu CC, Chen HS, et al. Serum IL-6, albumin and comorbidities are closely correlated with symptoms of depression in patients on maintenance haemodialysis. Nephrol Dial Transplant. 2011;26(2):658-664.

8. Wang LJ, Wu MS, Hsu HJ, et al. The relationship between psychological factors, inflammation, and nutrition in patients with chronic renal failure undergoing hemodialysis. Int J Psychiatry Med. 2012;44(2): $105-118$.

9. Saveanu RV, Nemeroff CB. Etiology of depression: genetic and environmental factors. Psychiatr Clin North Am. 2012;35(1):51-71.

10. Schloss P, Williams DC. The serotonin transporter: a primary target for antidepressant drugs. J Psychopharmacol. 1998;12(2):115-121.

11. Lesch KP, Gutknecht L. Pharmacogenetics of the serotonin transporter. Prog Neuropsychopharmacol Biol Psychiatry. 2005;29(6):1062-1073.

12. Coventry WL, James MR, Eaves LJ, et al. Do 5HTTLPR and stress interact in risk for depression and suicidality? Item response analyses of a large sample. Am J Med Genet B Neuropsychiatr Genet. 2010;153B(3):757-765.

13. Neumeister A, Hu XZ, Luckenbaugh DA, et al. Differential effects of 5-HTTLPR genotypes on the behavioral and neural responses to tryptophan depletion in patients with major depression and controls. Arch Gen Psychiatry. 2006;63(9):978-986.

14. Martinowich K, Lu B. Interaction between BDNF and serotonin: role in mood disorders. Neuropsychopharmacology. 2008;33(1): $73-83$.

15. Egan MF, Kojima M, Callicott JH, et al. The BDNF val66met polymorphism affects activity-dependent secretion of BDNF and human memory and hippocampal function. Cell. 2003;112(2):257-269. 
16. Rybakowski JK. BDNF gene: functional Val66Met polymorphism in mood disorders and schizophrenia. Pharmacogenomics. 2008;9(11): 1589-1593.

17. Gyekis JP, Yu W, Dong S, et al. No association of genetic variants in BDNF with major depression: a meta- and gene-based analysis. $A m J$ Med Genet B Neuropsychiatr Genet. 2013;162B(1):61-70.

18. Caldwell W, McInnis OA, McQuaid RJ, et al. The role of the val66met polymorphism of the brain derived neurotrophic factor gene in coping strategies relevant to depressive symptoms. PLoS One. 2013;8(6): e65547.

19. Kim JM, Stewart R, Bae KY, et al. Serotonergic and BDNF genes and risk of depression after stroke. J Affect Disord. 2012;136(3):833-840.

20. Kim JM, Kim SW, Stewart R, et al. Serotonergic and BDNF genes associated with depression 1 week and 1 year after mastectomy for breast cancer. Psychosom Med. 2012;74(1):8-15.

21. Zhou J, Li L, Tang S, et al. Effects of serotonin depletion on the hippocampal GR/MR and BDNF expression during the stress adaptation. Behav Brain Res. 2008;195(1):129-138.

22. Brunoni AR, Lopes M, Fregni F. A systematic review and metaanalysis of clinical studies on major depression and BDNF levels: implications for the role of neuroplasticity in depression. Int $J$ Neuropsychopharmacol. 2008;11(8):1169-1180.

23. Hashimoto K. Brain-derived neurotrophic factor as a biomarker for mood disorders: an historical overview and future directions. Psychiatry Clin Neurosci. 2010;64(4):341-357.

24. Bocchio-Chiavetto L, Bagnardi V, Zanardini R, et al. Serum and plasma BDNF levels in major depression: a replication study and meta-analyses. World J Biol Psychiatry. 2010;11(6):763-773.

25. Lee HY, Kim YK. Plasma brain-derived neurotrophic factor as a peripheral marker for the action mechanism of antidepressants. Neuropsychobiology. 2008;57(4):194-199.

26. Huang TL, Lee CT, Liu YL. Serum brain-derived neurotrophic factor levels in patients with major depression: effects of antidepressants. J Psychiatr Res. 2008;42(7):521-525.

27. Chen CK, Tsai YC, Hsu HJ, et al. Depression and suicide risk in hemodialysis patients with chronic renal failure. Psychosomatics. 2010;51(6): 528-528. e6.

28. American Psychiatric Association: Diagnostic and Statistical Manual of Mental Disorders, 4th ed (DSM-IV-TR). Washington, DC: American Psychiatric Association; 2000.

29. Sheehan DV, Lecrubier Y, Sheehan KH, et al. The Mini-International Neuropsychiatric Interview (MINI): the development and validation of a structured diagnostic psychiatric interview for DSM-IV and ICD-10. J Clin Psychiatry. 1998;59 Supp1 20:S22-S33.

30. Kuo CJ, Tang HS, Tsay CJ, Lin SK, Hu WH, Chen CC. Prevalence of psychiatric disorders among bereaved survivors of a disastrous earthquake in Taiwan. Psychiatr Serv. 2003;54(2):249-251.

31. Olssøn I, Mykletun A, Dahl AA. The Hospital Anxiety and Depression Rating Scale: a cross-sectional study of psychometrics and case finding abilities in general practice. BMC Psychiatry. 2005;5:46.

32. Chalder T, Berelowitz G, Pawlikowska T, et al. Development of a fatigue scale. J Psychosom Res. 1993;37(2):147-153.

33. Ware JE Jr, Sherbourne CD. The MOS 36-item short-form health survey (SF-36). I. Conceptual framework and item selection. Med Care. 1992;30(6):473-483.
34. Kurita M, Nishino S, Kato M, Numata Y, Sato T. Plasma brain-derived neurotrophic factor levels predict the clinical outcome of depression treatment in a naturalistic study. PLoS One. 2012;7(6):e39212.

35. Ozan E, Okur H, Eker C, Eker OD, Gönül AS, Akarsu N. The effect of depression, BDNF gene val66met polymorphism and gender on serum BDNF levels. Brain Res Bull. 2010;81(1):61-65.

36. Bhang S, Ahn JH, Choi SW. Brain-derived neurotrophic factor and serotonin transporter gene-linked promoter region genes alter serum levels of brain-derived neurotrophic factor in humans. J Affect Disord. 2011;128(3):299-304.

37. Quinn CR, Dobson-Stone C, Outhred T, Harris A, Kemp AH. The contribution of BDNF and 5-HTT polymorphisms and early life stress to the heterogeneity of major depressive disorder: a preliminary study. Aust N Z J Psychiatry. 2012;46(1):55-63.

38. Nederhof E, Bouma EM, Oldehinkel AJ, Ormel J. Interaction between childhood adversity, brain-derived neurotrophic factor val/met and serotonin transporter promoter polymorphism on depression: the TRAILS study. Biol Psychiatry. 2010;68(2):209-212.

39. Verhagen M, van der Meij A, van Deurzen PA, et al. Meta-analysis of the BDNF Val66Met polymorphism in major depressive disorder: effects of gender and ethnicity. Mol Psychiatry. 2010;15(3):260-271.

40. Lommatzsch M, Zingler D, Schuhbaeck K, et al. The impact of age, weight and gender on BDNF levels in human platelets and plasma. Neurobiol Aging. 2005;26(1):115-123.

41. Kobayakawa M, Inagaki M, Fujimori M, et al. Serum brain-derived neurotrophic factor and antidepressant-naive major depression after lung cancer diagnosis. Jpn J Clin Oncol. 2011;41(10):1233-1237.

42. Fábregas BC, MirandaAS, Barbosa IG, MouraAS, Carmo RA, TeixeiraAL. Brain-derived neurotrophic factor in patients with chronic hepatitis C: beyond neurotrophic support. Biol Psychiatry. 2012;72(4):e13-e14; author reply e15.

43. Birkenhäger TK, Geldermans S, Van den Broek WW, van Beveren N, Fekkes D. Serum brain-derived neurotrophic factor level in relation to illness severity and episode duration in patients with major depression. $J$ Psychiatr Res. 2012;46(3):285-289.

44. Chimienti G, Mezzapesa A, Rotelli MT, Lupo L, Pepe G. Plasma concentrations but not serum concentrations of brain-derived neurotrophic factor are related to pro-inflammatory cytokines in patients undergoing major abdominal surgery. Clin Biochem. 2012;45(9):631-636.

45. Pertosa G, Grandaliano G, Gesualdo L, Schena FP. Clinical relevance of cytokine production in hemodialysis. Kidney Int Suppl. 2000;76: S104-S111.

46. Bus BA, Tendolkar I, Franke B, et al. Serum brain-derived neurotrophic factor: determinants and relationship with depressive symptoms in a community population of middle-aged and elderly people. World J Biol Psychiatry. 2012;13(1):39-47.

47. Elfving B, Buttenschøn HN, Foldager L, et al. Depression, the Val66Met polymorphism, age, and gender influence the serum BDNF level. J Psychiatr Res. 2012;46(9):1118-1125.

48. Romanczyk TB, Weickert CS, Webster MJ, Herman MM, Akil M, Kleinman JE. Alterations in trkB mRNA in the human prefrontal cortex throughout the lifespan. Eur J Neurosci. 2002;15(2):269-280.
Neuropsychiatric Disease and Treatment

\section{Publish your work in this journal}

Neuropsychiatric Disease and Treatment is an international, peerreviewed journal of clinical therapeutics and pharmacology focusing on concise rapid reporting of clinical or pre-clinical studies on a range of neuropsychiatric and neurological disorders. This journa is indexed on PubMed Central, the 'PsycINFO' database and CAS

\section{Dovepress}

The manuscript management system is completely online and includes a very quick and fair peer-review system, which is all easy to use. Visit http://www.dovepress.com/testimonials.php to read real quotes from published authors. 